\title{
Protective Efficacy of Asparagus racemosus Root Extract and Isoprinosine against lonizing Radiation - induced Clastogenicity and Toxicity in Swiss Albino Mice
}

\author{
Sharmila Kameyanda Poonacha', Satheesh Kumar Bhandary Bavabeedu², Ronald Fernandes ${ }^{3, *}$, Suchetha Kumari Nalilu ${ }^{4}$, Vadisha Srinivas \\ Bhat $^{5}$, Jayarama Shetty Kolakebail ${ }^{6}$, Jerish Mangattu Jose ${ }^{6}$, Alex John Peter ${ }^{7}$ \\ 'Central Research Laboratory, K. S. Hegde Medical Academy, Nitte-Deemed to be University, Mangalore, Karnataka, INDIA \\ 2Department of ENT, K. S. Hegde Medical Academy, Nitte-Deemed to be University, Mangalore, Karnataka, INDIA. \\ ${ }^{3}$ Department of Pharmaceutical Chemistry, NGSM Institute of Pharma Sciences, Nitte -Deemed to be University, Paneer, Deralakatte, Mangalore, Karnataka, INDIA. \\ ${ }^{4}$ Department of Biochemistry, K. S. Hegde Medical Academy, Nitte-Deemed to be University, Mangalore, Karnataka, INDIA. \\ Department of ENT, K. S. Hegde Medical Academy, Nitte - Deemed to be University, Mangalore, Karnataka, INDIA. \\ ${ }^{6}$ Department of Oncology, Nitte Leela Narayan Shetty Memorial Cancer Institute, Mangalore, Karnataka, INDIA. \\ Apollo CBCC Cancer Care, Apollo Hospital, Gandhinagar, Gujarat, INDIA.
}

\begin{abstract}
Objective: We aimed to evaluate anticlastogenic and radioprotective potential of Asparagus racemosus root extract (ARE) and Isoprinosine (IPR) against electron beam radiation (EBR) induced clastogenicity and toxicity in Swiss albino mice. Methodology: In the pre-radiation study, the experimental animals were orally administered ARE - 200mg and IPR - 400mg/ $\mathrm{kg}$ b.wt once daily for 15 consecutive days. The animals exposed to sublethal dose (6Gy) of whole body EBR. Chromosomal aberration analysis and micronucleus assay were carried out in the bone marrow cells of the experimental animals. The various types of aberrations were scored and the micronuclei in Polychromatic Erythrocytes (PCE) and Nomochromatic Erythrocytes (NCE) were recorded. Assessment of Granulocyte Macrophage Colony Stimulating Factor (GM-CSF), was performed using mouse GM-CSF Picokine ELISA kit. Non-specific Alpha - esterase activity was determined by simultaneous azo dye coupling method. Dose Reduction Factor (DRF) was calculated to determine the protective role of ARE and IPR against EBR. Result: Treatment of mice with ARE-200 mg/kg b.wt and IPR-400 mg/kg b.wt decreased the percentage of the total aberration compared to the irradiated group; significantly reduced $(P<0.05)$ the frequency of $\mathrm{Mn}$ PCE and Mn NCE when compared with irradiation alone groups. Irradiation reduced the level of GM-CSF in the splenocytes which was
\end{abstract}

enhanced by the pre-treatment with ARE and IPR. There was a significant increase in the number of alpha-esterase positive cells in the pre-treatment group compared to radiation control. Increase in survival percentage was observed in the pre-treated mice when compared to radiation alone group. The DRF value of 1.11 and 1.04 was observed respectively. Conclusion: The present study suggests that the antioxidant potential of ARE and IPR could be of extreme significance in offering radioprotection and may be useful in combating various free-radical and reactive oxygen species mediated human pathological conditions.

Key words: Asparagus racemosus root extract, Isoprinosine, Electron beam radiation, Clastogenicity, Toxicity.

\section{Correspondence}

Dr. Ronald Fernandes, Professor, Department of Pharmaceutical Chemistry, NGSM Institute of Pharma Sciences Nitte-Deemed to be University, Paneer, Deralakatte Mangalore - 575018, Karnataka, INDIA

Phone: +91 9480115227

Email: ronaldfernandesv@gmail.com

DOI: 10.5530/jyp.2019.11.9

\section{INTRODUCTION}

Ionizing radiation has been reported to induce DNA damage, which in turn causes mutagenesis and carcinogenesis that is dependent on the total dose, dose rate, and animal species. ${ }^{1,2}$ In recent days, the need for nontoxic protective compounds is heightened due to radiation damage to normal tissues from occupational, therapeutic and accidental exposures and this has prompted interest in the discovery and development of medicinal plants and dietary compounds for protection against radiation-induced toxicity. ${ }^{3-5}$

Ionizing radiation is known to induce a wide array of molecular lesions in mammalian cells that can lead to diverse cellular responses namely cell inactivation, chromosomal rearrangements and mutations, eventually resulting in cancer and several genetic diseases. DNA damage occurs either by direct ionization or indirectly through generation of free radicals which attack DNA, thereby resulting in single-strand breaks and oxidative damage to sugar and base residues which may later be converted into DNA double strand-breaks (DSBs). It is reported that the unrepaired DSB will contribute to chromosomal aberrations. Aberrations like fragments, dicentrics and chromosomes with damaged kinetocore following division appear as micronuclei in the daughter cells. The micronucleus count gives an indirect measure of cytogenetic damage induced by any genotoxic agent and the inhibition of radiation-induced micronuclei indicates the radioprotective potential of any test agent. ${ }^{6}$

Cytogenetic damage induced by any genotoxic agent is indirectly measured by the micronucleus count. The inhibition of radiation induced micronuclei formation indicates the radioprotective efficacy of any test (herbal or chemical) agent. Radiation-induced aberrations in bone marrowderived cell populations are known to persist for months after irradiation as evidenced by several studies evaluating bone marrow cells and bone marrow stromal cells after irradiation. Radioprotective compounds, which can selectively protect normal tissues against radiation injury, is immensely useful; in association with protecting the normal tissue, it will also permit use of higher doses of radiation to obtain better cancer control and possible cure. However, till date no ideal radioprotectors are available as most synthetic compounds, including the Food and Drug

This is an open access article distributed under the terms of the Creative Commons Attribution-NonCommercial-ShareAlike 4.0 License, which allows others to remix, tweak, and build upon the work non-commercially, as long as the author is credited and the new creations are licensed under the identical terms. 
Administration (FDA), USA, approved aminothiol S-2-(3-aminopropylamino) ethyl phosphorothioic acid, [WR-2721, amifostine, ethiophos (USA), or gammaphos (former USSR)], are toxic at their optimal doses. Obviously, there has been a limited success of these agents in clinical applications. ${ }^{7-9}$

Plant-derived drugs provide an alternative to the synthetic compounds and are considered either non-toxic or less toxic than their synthetic counterparts. Herbs and their phytoconstituents, particularly with free radical scavenging, antioxidant properties, and immunostimulatory effects have been evaluated for their radioprotective efficacy. In the past two decades, preclinical studies have shown that some commonly used medicinal plants and their phytoconstituents possess radioprotective properties. Therefore, screening of natural products presents a major avenue for the discovery and development of novel radioprotective drugs. ${ }^{10-15}$

Asparagus racemosus belongs to family Asparagaceae commonly known by the name Shatavari, is one of the recognized drugs in Ayurveda, which is known to prevent aging, increase longevity, impart immunity, and improve mental function. Reports indicate that the pharmacological activities of $A$. racemosus root extract include antiulcer, antioxidant and immunomodulatory activities. This plant is grouped under the rejuvenator herbs which improves health by increasing immunity, imparting longevity as well as protection against stress. ${ }^{16-18}$

Isoprinosine has been shown to enhance production of cytokines such as IL-1, IL-2 and IFN $\gamma$. It increases the proliferation of lymphocytes in response to mitogenic or antigenic stimuli, increases active $\mathrm{T}$-cell rosettes and induces T-cell surface markers on prothymocytes. ${ }^{19}$

However, till date, no evidence is available on the anticlastogenic and radioprotective activity of Asparagus racemosus root extract and Isoprinosine against ionizing radiation-induced clastogenecity. Therefore, the present study is intended to investigate the anticlastogenic and radioprotective activity of Asparagus racemosus root extract and Isoprinosine using chromosomal aberration and micronucleus assays.

\section{MATERIALS AND METHODS}

\section{Collection of Plant Material}

Asparagus racemosus roots were collected from the Western Ghats region of Karnataka during March 2015 and were identified by a Taxonomist from Mangalore University, Karnataka.

\section{Preparation of Root Extracts Ethanolic Extract}

Asparagus racemosus (AR) roots were washed in distilled water, air dried and then dried in hot air oven at $40^{\circ}-50^{\circ} \mathrm{C}$ for a week. The dried plant material was powdered using mixer grinder and subjected to Soxhlet extraction with $99 \%$ ethanol for 48 hours. The mixture was evaporated to dryness in a rotary flash evaporator and stored in a refrigerator. The condensed extracts were used for preliminary screening of phytochemicals.

\section{Procurement of Isoprinosine}

Isoprinosine tablets were procured from Brandmedicines, European Union. (product code: 78/158)

\section{Ethical Clearance}

The Institutional Animal Ethics Committee of K.S Hegde Medical Academy, Nitte - Deemed to be University, has approved this study. (Ref. KSHEMA/IAEC/19/2015 dated 27.11.2015)

\section{Pre - radiation Study}

Animal Care and Handling

The guidelines set by WHO (World Health Organization, Geneva, Switzerland) was followed for animal care and handling. Swiss albino mice 6-8 weeks old, weighing 20-25 g taken from an inbred colony were used for the study. Six animals were housed in a polypropylene cage containing sterile paddy husk (procured locally) as bedding throughout the experiment. The animals were maintained under controlled conditions of temperature and light. They were provided with standard mice feed and water ad libitum.

\section{Pre-Treatment}

The animals were housed in the animal house and prior exposure to sublethal radiation dose, they were administered Asparagus racemosus ethanolic root extract (ARE) 200mg and Isoprinosine (IPR) $400 \mathrm{mg} / \mathrm{kg}$ b.wt orally via gavage once daily for 15 consecutive days. Meanwhile, control group and radiation control group were also maintained which were orally administered with distilled water. ARE and IPR were made into suspension using distilled water.

Food and water intake were recorded daily, whereas, body weight was recorded once in a week throughout the study period.

\section{Irradiation}

The animals were restrained in well- ventilated perspex box and exposed to sublethal dose $(6 \mathrm{~Gy})$ of whole-body electron beam radiation at a distance of $100 \mathrm{cms}$ from the beam exit point of the linear accelerator and at a dose rate of $3 \mathrm{~Gy} / \mathrm{min}$.

\section{Analysis of Cytogenetic damage \\ Chromosomal Aberration Analysis}

After the experimental period, $0.2-0.3 \mathrm{ml}$ of $0.025 \%$ of colchicine was injected intraperitoneally into the mice and left for one and a half hours. The experimental animals were sacrificed and the femur bone was removed and cleaned well. $0.5 \mathrm{ml}$ of $\mathrm{KCl}$ was taken in a syringe and bone marrow cells were flushed into a Petri dish, the suspension was mixed well and the analysis carried out according to the method of George and Kuttan. ${ }^{20}$ Chromosomal aberrations were scored under a light microscope. A total of 500 metaphase plates were scored per group and each aberration type was calculated in percentage.

\section{Micronucleus assay}

The mouse bone marrow micronucleus test was carried out according to the method described by Schmidt. ${ }^{21}$ The bone marrow from the femur of the experimental animals was flushed into a centrifuge tube containing 5\% Bovine serum albumin (BSA). The slides were stained with May-Grunwald's and Giemsa stain. 500 Polychromatic (PCE) and Normochromatic erythrocytes (NCE) were observed and counted under light Microscope. The micronuclei in PCE and NCE were recorded and micronuclei per 500 PCE and NCE cells were calculated.

\section{Assessment of Granulocyte - Macrophage Colony-Stimulating Factor (GM-CSF) production}

Mice were sacrificed and spleen tissue was isolated using ice-cold phosphate buffer saline. Single-cell suspensions were prepared by pressing isolated spleens through a cell strainer as described previously. ${ }^{22}$

To assess whether A. racemosus root extract and Isoprinosine could induce the production of GM-CSF, an enzyme-linked immunosorbent assay (ELISA) was performed in the prepared spleen cell suspension using mouse GM-CSF Picokine ELISA kit from Boster Biological Technology according to manufacturer's instructions. 


\section{Determination of alpha esterase activity}

Bone marrow was collected from the femur into the medium containing $2 \%$ bovine serum albumin and made into a single cell suspension. The number of cells was determined using hemocytometer.

Bone marrow cells from the above preparations were smeared on clean glass slides and stained with Fast blue base solution and Hematoxylin to determine the non-specific $\alpha$ - esterase activity by simultaneous azo dye coupling method following the Sigma Aldrich procedure no. $91 .^{23}$

The alpha ( $\alpha)$ - esterase positive cells were scored microscopically.

\section{Determination of dose reduction factor (DRF)}

DRF was calculated to determine the protective role of ARE and IPR against lethal Electron Beam Radiation [EBR]. For this, animals were divided into following groups ( $\mathrm{n}=10$ per group).

- Radiation alone group

Three groups of ten animals were maintained. They were orally administered. $1 \mathrm{ml} / 100 \mathrm{~g}$.b.wt. of distilled water orally for 15 consecutive days. One hour after of the last administration, they were exposed to 7, 9 and $11 \mathrm{~Gy}$ of EBR respectively.

\section{- $\quad$ ARE and IPR + radiation group}

Six groups of ten animals were maintained. They were orally treated with the optimal dose of $200 \mathrm{mg} / \mathrm{kg}$. b. wt. of ARE and $400 \mathrm{mg} / \mathrm{kg}$. b.wt. of IPR once daily for 15 consecutive days and after the last dose, i.e., on the $15^{\text {th }}$ day, animals were exposed to 7, 9 and 11 Gy of EBR respectively.

The animals of all the groups (radiation alone, ARE and IPR + radiation) were observed daily for up to 30 days post-irradiation for signs of radiation sickness and mortality. The DRF was calculated according to the method of Miller and Tainter ${ }^{24}$ as follows:

$$
\text { Dose reduction factor }=\frac{\mathrm{LD} \mathrm{50/30} \text { of treated group }+ \text { irradiation }}{\mathrm{LD} 50 / 30 \text { of irradiation alone animals }}
$$

\section{Statistical Analysis}

The data are expressed as Mean \pm SD. Analysis of variance (ANOVA) was used to make the statistical comparison between the groups followed by Tukey's multiple comparison tests using Prism 3.0 software. Dose reduction factor was calculated from the ratio of $\mathrm{LD}_{50} / 30$ of treated group + radiation to radiation alone group.

The criterion for statistical significance was taken as $P<0.05$.

\section{RESULTS}

\section{Effect of ARE and IPR Pre-Treatment on}

\section{Chromosomal Aberrations and Micronucleus} Formation

In the present study, control mice showed less percentage of aberrant cells while radiation treatment (whole body 6Gy radiation) showed an increase in the percent of aberrant cells. A corresponding increase was found in all the individual aberrations. Treatment of mice with ARE at $200 \mathrm{mg} / \mathrm{kg}$ b.wt and IPR at $400 \mathrm{mg} / \mathrm{kg}$ bwt resulted in a decreased percentage of total aberration and number of aberrations per cell compared to the irradiated group. There was a decrease in all types of aberrations (Table 1). Metaphase chromosome preparation from bone marrow cells of control and treatment groups is shown in Figure 1.

Pretreatment with ARE and IPR significantly reduced $(P<0.05)$ the frequency of Mn PCE and Mn NCE when compared with irradiation alone groups (Table 2). Micronuclei formation in the bone marrow preparation of experimental animals is shown in Figure 2A-NCE and $\mathrm{Mn}$ NCE and Figure 2B-PCE and Mn PCE.
Table 1: Effect of ARE and IPR pre-treatment on radiation induced chromosomal aberrations in swiss albino mice.

\begin{tabular}{|c|c|c|c|c|c|c|c|}
\hline 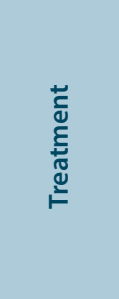 & 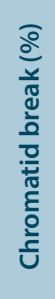 & 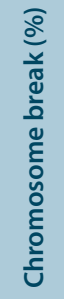 & $\begin{array}{l}\text { } \\
\text { } \\
\text { o } \\
\frac{c}{0} \\
\frac{c}{y} \\
x\end{array}$ & $\frac{\mathfrak{a}}{a}$ & 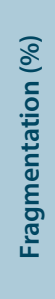 & $\begin{array}{l}\frac{a}{0} \\
\frac{\lambda}{0} \\
\frac{0}{0} \\
\frac{2}{0} \\
0\end{array}$ & 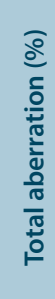 \\
\hline Control & 0.5 & 0 & 0 & 0.75 & 0.5 & 1.0 & 2.75 \\
\hline $\mathrm{RC}(6 \mathrm{~Gy})$ & 8.5 & 10.5 & 9 & 15 & 8 & 2.0 & 53 \\
\hline ARE & 4 & 4 & 4 & 7 & 2.5 & 1.5 & 23 \\
\hline IPR & 5 & 4 & 5 & 8 & 3 & 2.0 & 27.0 \\
\hline
\end{tabular}
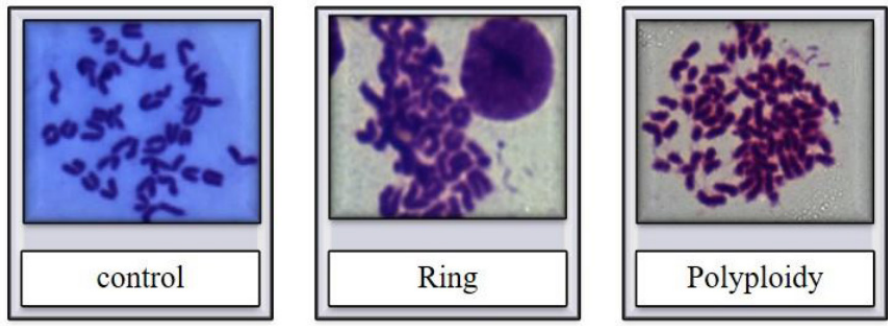

Figure 1: Metaphase chromosome preparation from bone marrow cells of control and treatment groups.

Table 2: Effect of ARE and IPR pre-treatment on radiation induced micronuclei formation in swiss albino mice.

\begin{tabular}{ccc}
\hline Treatment & $\begin{array}{c}\text { MnPCE/ 500PCE } \\
(\text { mean } \pm \text { SD) }\end{array}$ & $\begin{array}{c}\text { MnNCE/ 500NCE } \\
\text { (mean } \pm \text { SD) }\end{array}$ \\
\hline Control & $5.5 \pm 0.70$ & $0 \pm 0$ \\
RC(6Gy) & $34 \pm 9.9$ & $4.5 \pm 0.70$ \\
ARE & $6.5 \pm 2.1$ & $1 \pm 0.12$ \\
IPR & $24.5 \pm 2.1$ & $2.5 \pm 0.70$ \\
\hline
\end{tabular}

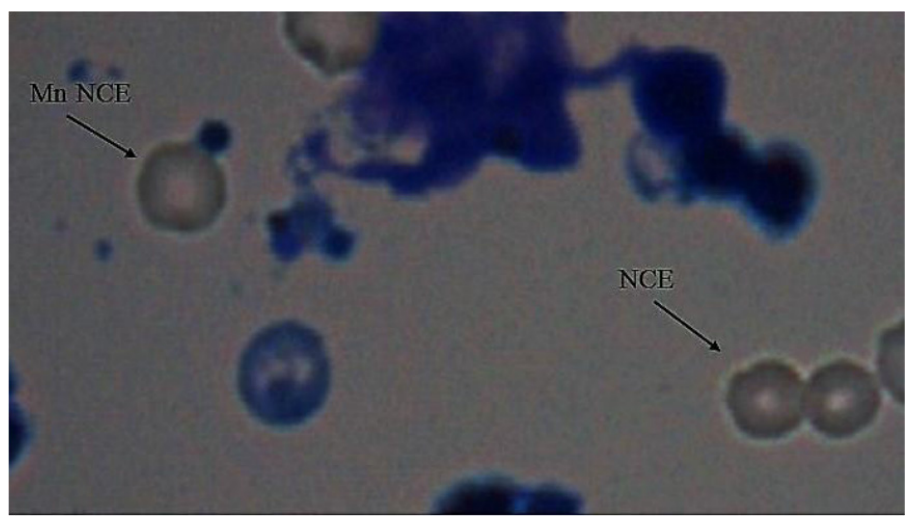

Figure 2A: Normochromatic Erythrocytes (NCE) and Micronucleated Normochromatic Erythrocytes (MnNCE). 


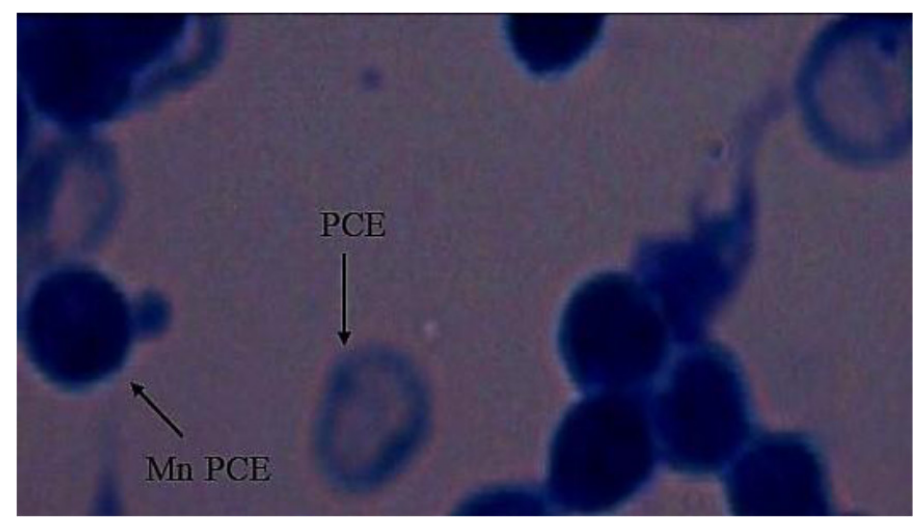

Figure 2B: Polychromatic Erythrocytes (PCE) and Micronucleated Polychromatic Erythrocytes (MnPCE).

\section{Pre radiation GMCSF}

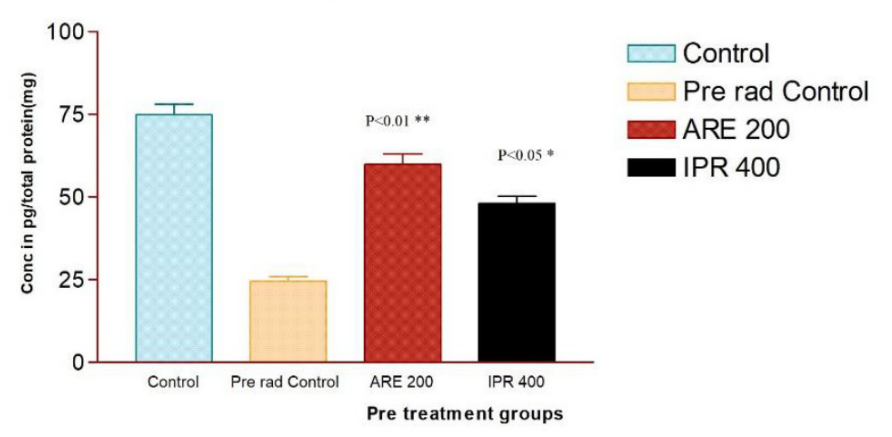

Figure 3: Effect of ARE and IPR pre-treatment on Granulocyte Macrophage Colony-Stimulating Factor (GM-CSF).

\section{Effect of ARE and IPR pre-treatment on Granulocyte Macrophage Colony Stimulating Factor and alpha esterase activity}

Effect of ARE and IPR pre-treatment on Granulocyte Macrophage Colony-Stimulating Factor (GM-CSF) is represented graphically in Figure 3. From the present study, it is evident that irradiation reduced the level of GM-CSF in the splenocytes which was significantly enhanced by the pre-treatment with Asparagus racemosus root extract $(P<0.01)$ and Isoprinosine $(P<0.05)$ compared to pre-radiation control.

The effect of ARE and IPR pre-treatment on alpha-esterase positive cells is shown in Table 3. The numbers of alpha esterase positive cells in irradiated control animals were found to be reduced compared to the control group. In the case of ARE and IPR pre-treated animals, there was a significant increase in the number of alpha-esterase positive cells compared to radiation control. $P<0.05$ was observed in the pre-treatment groups compared to pre-radiation control.

\section{Dose Reduction Factor of ARE and IPR}

Increase in survival percentage was observed in ARE treated and irradiated mice when compared to radiation alone group. The $\mathrm{LD}_{50} / 30$ was found to be 9 Gy for radiation alone. Although, it was increased to $10 \mathrm{~Gy}$ after ARE treatment resulting in increased $\mathrm{LD}_{50} / 30$ value by $1.0 \mathrm{~Gy}$. The DRF of 1.11 was observed (Figure 4).

IPR administered group also exhibited an increase in survival of mice when compared with radiation alone group. The $\mathrm{LD}_{50} / 30$ was found to be 9 Gy for radiation alone. Although, it was increased to 9.4 Gy after
Table 3: Effect of ARE and IPR pre-treatment on alpha esterase activity in irradiated mice.

\begin{tabular}{cc}
\hline Treatment & $\begin{array}{c}\boldsymbol{\alpha} \text { - Esterase positive cells/1000cells } \\
\text { (Mean } \pm \text { SD) }\end{array}$ \\
\hline Control & $317 \pm 8.0$ \\
Pre - radiation Control & $91 \pm 3.0$ \\
ARE 200 + radiation & $171 \pm 4.8$ \\
IPR 400 + radiation & $119 \pm 5.1$ \\
\hline
\end{tabular}

\section{DRF ARE}

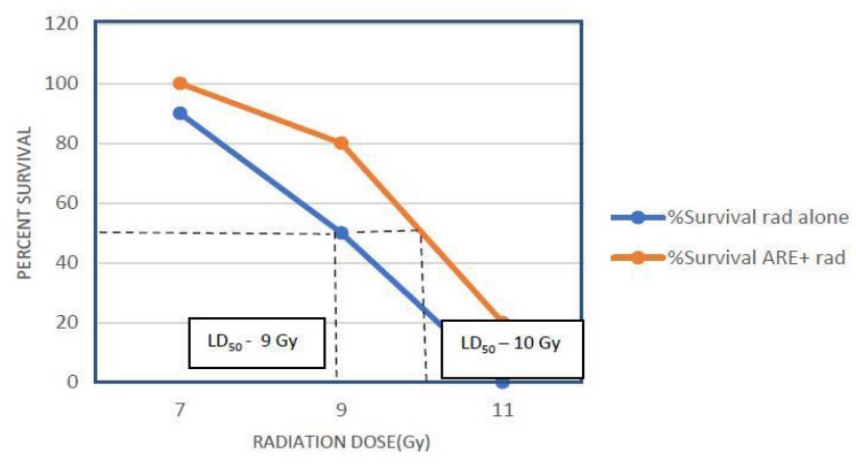

Figure 4: DRF-ARE.

\section{DRF IPR}

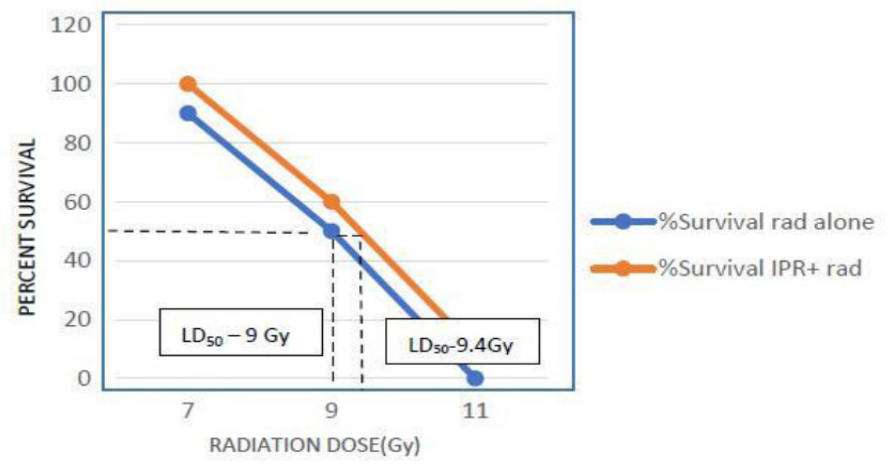

Figure 5: DRF-IPR,

IPR treatment resulting in increased $\mathrm{LD}_{50} / 30$ value by $0.4 \mathrm{~Gy}$. The DRF of 1.04 was observed (Figure 5).

\section{DISCUSSION}

Chromosomal aberrations (CAs) are observed as breaks, dicentrics, acentrics, fragments, rings, and translocations in cells when they are exposed to ionizing radiation during the G0 or G1 phases of the cell cycle. These CAs are used as biomarkers of radio sensitivity or radiation damage following medical, accidental and occupational exposure. There is evidence which suggest that some of these CAs may be strongly linked with different cancer types. ${ }^{25-27}$ In addition, radiation is well-known to generate free radicals which cause chromosomal damages. The use of certain materials may aid in decreasing the genotoxicity caused by radiation and may inhibit mutagenesis and carcinogenesis. ${ }^{28}$

In the present study, it was observed that the frequency of aberrant cells: chromatid breaks, chromosome breaks, centric rings, exchanges, acentric 
fragments, and polyploidy significantly increased in bone marrow cells of animals exposed to 6 Gy electron beam radiation (EBR). A significant increase in the percent aberrant metaphases as well as different aberrations, is known to be produced during radiation exposure. Chromosomal damage is manifested as breaks and fragments, which would later appear as micronuclei in the rapidly proliferating cells.

In several published studies, a number of possible mechanisms for the observed decrease in the frequency of CAs have been described although the specific mechanism responsible for the observed effect of ARE and IPR in reducing the frequency of chromosome aberrations was not evaluated in this study. Since Electron Beam Radiation (EBR) is known to induce cellular damage mediated through oxidative processes, it is possible that the significant reduction in observed chromosomal damage in the ARE and IPR pre-treatment group compared to the radiation alone group is the result of the direct antioxidant properties of ARE and IPR or that it occurs indirectly through the induction of antioxidants like glutathione and increases in enzymes like superoxide dismutase and catalase. $^{29,30}$

Radioprotectors are known to offer protection to cells by scavenging the Reactive Oxygen Species (ROS) generated by ionizing radiation which is mediated through free radical scavenging mechanism and another mechanism includes hydrogen atom donation which facilitate direct repair at sites of DNA damage. Radioprotectors scavenge the ROS generated by ionizing radiation before they can interact with biochemical molecules, thus reducing the deleterious effects of radiation. Therefore, antioxidant and free radical scavenging properties may be suggested to be the likely mechanism of radiation protection. ${ }^{31,32}$

The induction of different types of lesions in the DNA by ionizing radiation namely, single and Double strand breaks (DSB), base damage, as well as DNA cross-links (DNA-DNA and DNA-Protein) is well established. Amongst these, DNA DSBs have been considered the critical lesion for the radiation-induced chromosome break and cell death. Several studies have established a correlation between the induction of cell death and chromosome aberrations and the frequency of micronuclei formation. Acentric fragment(s) or sometimes the whole chromosome (with defective kinetocore) will lead to the formation of micronuclei. An increase in the micronuclei frequency during the interphase after the first post-treatment mitosis is observed due to the induction of cytogenetic damage by radiation and clastogenic agents on the mitotic cell. Moreover, it is understood that nonrepair/ misrepair of the DNA double-strand breaks contributes to the chromosomal aberrations which could be quantitatively analyzed by the scoring of micronuclei formation in the cells. ${ }^{33,34}$

Therefore, the micronucleus assay is a very useful parameter used for evaluating cytogenetic damage and is very extensively used in the screening of cyto-protective / radio-modifying potential of natural and synthetic products. Our study demonstrated that ARE and IPR were effective in counteracting the clastogenic effect of radiation, thereby offering radioprotection as assessed by the micronucleus assay. It is interesting to note that ARE and IPR were very effective in ameliorating the effect of radiation at 200 and $400 \mathrm{mg} / \mathrm{kg}$ b.wt in mice. In the present study, we report for the first time the radio protective and anticlastogenic potential of ARE and IPR. Although at this stage, the exact mechanism of action of ARE and IPR on radioprotection is far from being understood, the available information on the antioxidant potential of ARE and IPR obtained from the present investigation supports the free radical scavenging mediated pathways. ${ }^{35}$

The earlier report on the phytoconstituents of the roots of Asparagus racemosus indicated the presence of saponins, flavonoids, tannins, free amino acids, carbohydrates, vitamin- $\mathrm{C}$, and sterols. Therefore, the presence of some of these constituents may have rendered radio protective and anticlastogenic effect. Besides, the roots may also have other unidentified bioactive compounds. Therefore, although ARE and IPR is capable of imparting a radio protective effect, at this stage it is not possible to attribute the observed effect to any one of the bioactive principles of the roots as the degree of protection will depend on the effect of these agents either singly or collectively against radiation-induced cytogenetic damage. ${ }^{36}$

Granulocyte Macrophage Colony Stimulating Factor (GM-CSF) is one of the major hematopoietic growth factors; belongs to a family of glycoproteins. It is mainly produced by $\mathrm{T}$ lymphocytes or non-hematopoietic cells and stimulates proliferation and function of a wide variety of myeloid progenitor cell. ${ }^{37}$

Radiation injuries is a complex clinical challenge and its management requires careful use of mitigation as well as therapeutic agents, administered at suitable times following the exposure. Available evidence from literature supports the concept that various colony stimulating factors viz. G-CSF, GM-CSF etc. significantly enable recovery from radiationinduced hematopoietic injury and thus, enhance the survival of individuals experiencing acute radiation syndrome. ${ }^{38}$

Naphthyl acetate esterase activity in the bone marrow is an indicator of maturation of stem cells to monocytes-macrophages. A number of bone marrow positive cells for non-specific esterase were found to increase after ARE and IPR treatment which indicates the maturation of cells of monocyte/macrophage lineage. One of the mechanism may be by the induction of proliferation of bone marrow stem cells either directly or indirectly stimulating the release of factors that are involved in the regulation of hemopoiesis. ARE and IPR were found to enhance the number of esterase positive cells that support the above data. ${ }^{39}$

The DRF is defined as the ratio of radiation doses required to produce the same biologic effect in the absence and presence of the radioprotector. The protective capacity of an agent (chemical or plant extract) is expressed as Dose Reduction Factor (DRF). ${ }^{40}$

The extent of protection against radiation damage is most commonly assessed either by comparing percentage survival between the treated and the control groups at a selected lethal radiation dose, or by computing a dose reduction factor (DRF) for the drug under study. To determine the DRF, groups of treated and control animals are exposed to several levels of radiation and observed for survival from day 1 to day 30 . The $\mathrm{LD}_{50}$ of radiation is determined for the control group and the treatment groups. ${ }^{41}$ In animal studies, DRF is determined by irradiating the experimental animals with and without administering the test agent at a range of radiation doses and then comparing the endpoint of interest. Unfortunately, DRFs have not been reported often for plant-derived compounds. In mice model, DRF for naturally occurring compounds are not likely to be greater than 1.3 whereas high DRFs $(>2.0)$ may be obtained with synthetic drugs. ${ }^{42}$

Assessment of DRF for 30-day survival $\left(\mathrm{LD}_{50} / 30\right)$ allows for a comparison of potential agents that protect against radiation-induced hematopoietic mortality in mouse model. Naturally occurring antioxidant compounds namely, vitamin E (alpha-tocopherol), demonstrated a DRF of 1.11 (95\% CI) when given within $15 \mathrm{~min}$ after TBI in CD2F1 mice. ${ }^{43}$ In our study, we demonstrated that ARE + radiation afforded a better DRF (1.11) than IPR + radiation with DRF value of 1.04 , when given 15 days orally before total body irradiation.

In our present study, the radio protective effect of ARE and IPR was demonstrated by the $\mathrm{LD}_{50} / 30$ values and $\mathrm{DRF}$ of 1.11 and 1.04 respectively, which is apparently quite high and therefore demonstrates the efficacy of ARE and IPR as potent radio protectors.

\section{CONCLUSION}

From the present study, it can be concluded that in order to understand the mechanism of radioprotection exhibited by ARE and IPR, its bioactive components need to be isolated, purified and characterized. The antioxidant potential of ARE and IPR in reducing radiation-induced clastogenicity 
Sharmila, et al:: Asparagus racemosus Root Extract and Isoprinosine Attenuates Ionizing Radiation induced Clastogenicity and Toxicity

may also be due to the induction of phase II antioxidative enzymes such as superoxide dismutase, catalase etc., Therefore, there is a need for extensive exploration of the radio protective efficacy of ARE and IPR and its active principles by using human cell lines. In addition to its anticlastogenic property, the present observation of the antioxidant potential of ARE and IPR could be of extreme significance in offering radioprotection and may be useful in combating various free-radical and reactive oxygen species-mediated human pathological conditions.

\section{ACKNOWLEDGEMENT}

The authors would like to extend earnest gratitude to the Board of Research in Nuclear Sciences, Department of Atomic Energy, Government of India for providing the financial support (Sanction No. 34(1)/14/32/2014-BRNS). The authors remain grateful to Nitte (Deemed to be University) for providing laboratory facilities and also would like to acknowledge Dr.K.R Chandrashekar, Chairman, Department of Applied Botany, Mangalore University, Karnataka, India for the identification of the study plant.

\section{CONFLICT OF INTEREST}

The authors declare no conflict of interest.

\section{ABBREVIATIONS}

ANOVA: Analysis of Variance; ARE: Asparagus racemosus Ethanol; $\boldsymbol{\alpha}$ : Alpha; b.wt: Body weight; CA: Chromosomal Aberration; DNA: Deoxyribo nucleic acid; DRF: Dose reduction Factor; DSB: Double Strand Break; EBR: Electron Beam Radiation; ELISA: Enzyme Linked Immunosorbent Assay; FDA: Food and Drug Administration; GM-CSF: Granulocyte Macrophage Colony Stimulating Factor; Gy: Gray; IPR: Isoprinosine; Kg: Kilogram; KCl: Potassium Chloride; mg: milligram; NCE: Normochromatic Erythrocytes; PCE: Polychromatic Erythrocytes; ROS: Reactive Oxygen Species; TBI: Total Body Irradiation; WHO: World Health Organization; WR-2721: Walter Reed Army Institute.

\section{REFERENCES}

1. Goodhead DT. Initial events in the cellular effects of ionizing radiations: clustered damage in DNA. Int J Radiat Biol. 1994;65(7):17.

2. Iyer $R$, Lehnert BE. Effects of ionizing radiation in targeted and nontargeted cells. Arch Biochem Biophys. 2000;376(1):14-25

3. Hall EJ, Giaccia AJ. Radiobiology for the Radiologist. $7^{\text {th }}$ ed. Philadelphia, PA: Lippincott. USA: Williams and Wilkins. 2012;148

4. Arora R, Gupta D, Chawla R, Sagar R, Sharma A, Kumar R, et al. Radioprotection by plant products: Present status and future prospects. Phytother Res. 2005;19(1):1-22

5. Hosseinimehr SJ. Trends in the development of radioprotective agents. Drug Dis Today. 2007;12(19-20):794-805

6. Breen AP, Murphy JA. Reactions of oxyl radicals with DNA. Free Radic Biol Med. 1995;18(6): 1033-77.

7. Sonntag VC. The chemistry of free-radical-mediated DNA damage. Basic Life Sci. 1991;58:287-317.

8. Countryman PI, Heddle JA. The production of micronuclei from chromosome aberrations in irradiated cultures of human lymphocytes. Mutat Res. 1976;41(2):321-32

9. Greenberger JS, Anderson J, Berry LA, Epperly M, Cronkite EP, Boggs SS Effects of irradiation of CBA/CA mice on hematopoietic stem cells and stromal cells in long-term bone marrow cultures. Leukemia. 1996;10(3):514-27.

10. Hosseinimehr SJ. Trends in the development of radioprotective agents. Drug Dis Today. 2007;12(19-20):794-805.

11. Byers T, Perry G. Dietary carotenes, vitamin $\mathrm{C}$ and vitamin $\mathrm{E}$ as protective antioxidants in human cancers. Annu Rev Nutr. 1992;12(1):139-59.

12. Uma DP, Ganasoundari A, Vrinda B, Srinivasan KK, Unnikrishnan MK. Radiation protection by the ocimum flavonoids orientin and vicenin: mechanisms of action. Radiat Res. 2000;154(4):455- 60.

13. Jagetia GC, Venkatesha VA. Effect of mangiferin on radiation-induced micronucleus formation in cultured human peripheral blood lymphocytes. Environ
Mol Mutagen. 2005;46(1):12-21.

14. Arora R, Gupta D, Chawla R. Radioprotection by plant products: Present status and future prospects. Phytother Res. 2005;19(1):1-22.

15. Jagetia GC, Baliga MS. Influence of the leaf extract of Mentha arvensis Linn (mint) on the survival of mice exposed to different doses of gamma radiation. Strahlenther Onkol. 2002;178(2):91-8.

16. Visavadiya NP, Soni B, Madamwar D. Suppression of reactive oxygen species and nitric oxide by Asparagus racemosus root extract using in vitro studies. Cell Mol Biol. 2009;55:1083-95.

17. Hossain, et al. Investigation of cytotoxicity and in-vitro antioxidant activity of Asparagus racemosus root extract. Int Curr Pharm J. 2012;1 (9):250-7.

18. Puri HS. Rasayana- Shatawari, In: Ayurvedic herbs for longevity and rejuvenation London: Taylor and Francis. 2003;255.

19. Huttenlocher PR, Mattson RH. Isoprinosine in subacute sclerosing panencephalitis. Neurology. 1979;29(6):763-71.

20. George K, Kuttan R. Lack of induction of chromosome aberrations and micronuclei by $\mathrm{N}$-(1,3-dimethylbutyl)-N-phenylparaphenyl enediamine in mouse bone marrow cells. Mutat Res.1996;370(3-4):191-4.

21. Schmidt W. The Micronucleus test. Mutat Res. 1975;31:9-15

22. Park E, Ahn GN, Lee NH, Kim JM, Yun JS, Hyun JW, et al. Radioprotective properties of eckol against ionizing radiation in mice. FEBS Letters. 2008;582(6):925-30.

23. Li CY, Lam KW, Lam LT. Esterase in human leukocytes. J Histochem Cytochem. 1973;21(1):112-3.

24. Miller NJ, Miller LC, Tainter ML. Estimation of the ED50 and its error by means of logarithmic probit graph paper. Proc Soc Exp Biol Med. 1944;57(2):261.

25. Garcia VML, Chen RL, Powell FR, Hirsch TC, Kennedy R, Keith YE, et al. Spectral karyotyping detects chromosome damage in bronchial cells of smokers. Am J Respir Crit Care Med. 2007;176(5):505-12.

26. Hande MP, Azizova TV, Burak LE, Khokhryakov VF, Geard CR, Brenner CR Complex chromosome aberrations persist in individuals many years after occupational exposure to densely ionizing radiation: And FISH study. Gene Chromosome Canc. 2005;441(1):1-9.

27. Atanasova P, Hadjidekova V, Agova S, lovtchev M. Chromosomal aberrations in radiation waste repository workers detected by fish painting and Giemsa staining. Turk J Med Sci. 2004;34(6):359-65.

28. Flora SJ, Bhadauria S, Kannan GM, Singh N. Arsenic-induced oxidative stress and the role of antioxidant supplementation during chelation: A review. J Environ Biol. 2007;28(2):333-47.

29. Li Y, Cao Z, Zhu H. Upregulation of endogenous antioxidants and phase 2 enzymes by the red wine polyphenol, resveratrol in cultured aortic smooth muscle cells leads to cytoprotection against oxidative and electrophilic stress. Pharmacol Res. 2006;53(1):6-15. [PubMed: 16169743]

30. Losa GA. Resveratrol modulates apoptosis and oxidation in human blood mononuclear cells. Eur J Clin Invest. 2003;33(9):818-23. [PubMed: 12925042]

31. Gasson JC. Molecular physiology of granulocyte macrophage colony stimulating factor. Blood. 1991;77:1131-45.

32. lliakis G. The role of DNA double strand breaks in ionizing radiation-induced killing of eukaryotic cells. Bioessays. 1991;13(12):641-8.

33. Ward JF. The complexity of DNA damage: relevance to biological consequences. Int J Radiat Biol.1994;66(5):427-32.

34. Midander J, Revesz L. The frequency of micronuclei as a measure of cell survival in irradiated cell populations. Int J Radiat Biol Relat Stud Phys Chem Med. 1980;38(2):237-42

35. Jagetia GC, Venkatesha VA. Effect of mangiferin on radiation-induced micronucleus formation in cultured human peripheral blood lymphocytes. Environ Mol Mutagen. 2005;46(1):12-21.

36. Rao BSS, Devi PU. Response of $\mathrm{S} 180$ murine tumor to bleomycin in combination with radiation and hyperthermia using micronucleus assay: a multimodality approach for therapeutic augmentation. Indian J Exp Biol. 2005;43(7):96-600

37. Gasson JC. Molecular physiology of granulocyte macrophage colony stimulating factor. Blood. 1991;77:1131-45.

38. Singh VK. Animal models for acute radiation syndrome drug discovery. Expert Opin Drug Discov. 2015;10(5):497-517.

39. Bancroft JD, Cook HC. Manual of Histologic Tehniques. Churchill Livingstone London. 1994;171.

40. Eric HJ. Radiobiology for the radiologist / Eric J. Hall. Amato J Giaccia. $7^{\text {th }}$ ed. 129

41. Weiss JF, Landauer MR. History and development of radiation-protective agents. Int J Radiat Biol. 2009;85(7):539-73.

42. Weiss JF, Landauer MR. Protection against ionizing radiation by antioxidant nutrients and phytochemicals. Toxicology. 2003;189(1-2):1-20.

43. Srinivasan V, Weiss JF. Radioprotection by vitamin E: injectable vitamin E administered alone or with WR-3689 enhances survival of irradiated mice. Int J Radiat Oncol Biol Phys. 1992;23(4):841-5.

Article History: Submission Date : 25-06-2018 ; Revised Date : 20-09-2018; Acceptance Date : 20-10-2018.

Cite this article: Poonacha SK, Bhandary SKB, Fernandes R, Nalilu SK, Bhat VS, Kolakebail JS, Jose JM, Peter AJ. Protective Efficacy of Asparagus racemosus root extract and Isoprinosine against lonizing Radiation - induced Clastogenicity and Toxicity in Swiss Albino Mice. J Young Pharm. 2019;11(1):40-5. 